\title{
"MODIFICAÇÕES DA IMAGEM DA ENFERMEIRA, PERCEBIDAS PELOS ESTUDANTES, DURANTE O CURSO DE GRADUAÇÃO DE ENFERMAGEM"
}

\author{
Ieda Barreira de Castro * \\ Neiva Lunardi ** \\ Anice Maria Coloriti ***: \\ Francimar de Moura $* * * *$
}

\section{i - O PROBLEMA}

\subsection{Introdução:}

Uma profissão surge para atender a uma necessidade social, que decorre do processo de desenvolvimento da comunidade. Quanto mais acelerado este processo maior tem que ser a capacidade de adaptação da profissão a essas mudanças.

Mayor (1963) faz um paralelo entre as fases de crescimento e desenvolvimento de qualquer profissão e do ser humano considerando os períodos de infância, adolescência e de maturidade. Nenhuma profissão nasce na idade adulta. A visão de qualquer grupo profissional nesta perspectiva possibilita melhor avaliação de seu "status" e maior compreensão do papel perante a sociedade.

Nestes cinqüenta anos de existência a Enfermagem no Brasil vem atravessando as suas fases de crescimento. Julgamos poder situá-la no início da fase adulta, necessitando ainda expandir a sua atividade de pesquisa, para atingir a maturidade.

Em 1949, a Lei 775 e o seu Regulamento, que dispõem sobre o ensino de Enfermagem no país, fixaram um currículo de trinta e seis meses de duração incluídos os trabalhos práticos e os estágios. Entretanto não houve alterações qualificativas de importância no

\footnotetext{
* Supervisora da Divisãc Nacinoal de Tuberculose.

* * Professora do Curso de Auxiliar de Enfermagem da Universidade Católica de Pelotas, RS.

*** Diretora da Escola de Auxiliares de Enfermagem N. S. de Fátima, Caxias do Sul, RS.

**** Auxiliar de Ensino da Escola Ana Néri, UFRJ .-. GB.
} 
conteúdo programático, prevalecendo a ênfase na parte prática. A fundamentação teórica dos procedimentos de enfermagem continuou a ser negligenciada.

Há cerca de dez anos, as Escolas de Enfermagem passaram a exigir das suas candidatas o certificado de conclusão do segundo ciclo secundário. Na mesma época o Parecer 271/62 do Conselho Fe(leral de Educação fixou o Currículo Mínimo para os Cursos de Enfermagem. Este fato marca o início de uma nova fase para a enfermagem brasileira. A Reforma Universitária, decorrente dos decretos n.o 53/66 e 252/67, veio apressar a evolução das escolas e a sua integração nas Universidades, através da implantação de um sistema comum de ensino e pesquisa, pela concentração das matérias basicas em unidades próprias. Atualmente estão saindo das Universidades os primeiros produtos educacionais dessa reforma.

O estudante de enfermagem, ao ingressar no Curso de Graciuacâo, traz consigo o esterótipo da enfermeira mantido pela sociedade. cabendo às Escolas oferecer-lhe uma imagem mais compatível com o tipo profissional que desejam formar, isto é, que esteja ajustado às normas éticas aprovadas pela classe e à realidade do país. Em 1967, o XIX Congresso Brasileiro de Enfermagem, considerando" (2 ) que a reforma Universitária abriria perspectivas para um revigoramento dos cursos de Graduação para enfermeiras, dependendo todavia da oportunidade que tiverem as educadoras de enfermagem cie interpretar para a Universidade a que pertencem, os objetivos do ensino profissional de enfermagem, recomendou às Diretoras e a. Corpo Docente de Enfermagem (b) que se desse prioridade, nos planos de trabalho, a uma campanha de divulgação sobre a profissāo, procurando criar uma nova imagem da enfermeira".

Esperamos que este trabalho sirva de referência a estudos posteriores que possam ampliar o conhecimento do problema e que o cstudo do assunto seja útil à avaliação dos currículos dos Cursos de Graduação em Enfermagem.

\subsection{Hipóteses de trabalho:}

O Currículo do Curso de Graduação altera a imagem da enfermeira que a aluna de enfermagem traz ao ingressar na escola.

As modificacões da imagem da enfermeira percebidos pelos estudantes variam entre as escolas frequentadas.

\section{2 - REVISÃO DA LITERATURA}

Sobre o assunto existem estudos estrangeiros, entretanto, no Brasil, os diversos trabalhos que abordam o tema não resultaram 
de investigação específicas. Também não relacionam o problema com o comportamento dos alunos do Curso de Graduação.

\subsection{A Evolução de Enfermagem no Brasil:}

Em 1963, Alcântara, preocupada com o assunto claborou uma tese sobre "A ENFERMAGEM MODERNA COMO CATEGORIA PROFISSIONAL. OBSTÁCULOS A SUA EXPANSÃO NA SOCIEDADE BRASILEIRA". A pesquisa foi realizada $\in \mathrm{em} 1961$ e 1962 na cidade de Ribeirão Preto, localizada em uma região desenvolvida do Estado de São Paulo, e foi publicada em São Paulo em 1966.

Pela análise da situação histórico-cultural, apesar da falta de ciados referentes ao pessoal de enfermagem que trabalhava nos hospitais brasileiros no passado, a autora deduziu que na década de vinte, época da implantação da enfermagem profissional no Brasil, as condições da sociedade brasileira eram muito mais desfavoráveis do que as prevalescentes na Inglaterra e nos Estados Unidos na segunda metade do século XIX, quando emergia naqueles países a enfermagem moderna. Constata, entretanto, que transformações ocorridas no Brasil em diversos setores da vida social repercutiram favoravelmente sobre a profissão, permitindo elevar o "status" da enfermeira diplomada, colocando-a na hierarquia de prestígio de profissões em torno da medicina, junto àquelas que exigem formação especializada. Definiu a autora, como características da profissão na época, a predominância dos elementos do sexo feminino entre os profissionais, o reduzido número de pessoas que compunham a classe em relação a outras classes e o mercado de trabalho em expansão.

Sugeriu que a elevação das escolas de enfermagem a estabelecimentos de nivel superior seria fator para atrair maior número de candidatos à profissão.

\subsection{A Enfermeira do Estado da Guanabara}

Em 1971, estudo realizado no Estado da Guanabara por Castro, C.L.M. e outros, tendo como objetivo, além dos enfermeiros, também os dentistas, os farmacêuticos, os médicos e cs veterinários, nos dá uma visão dos "status" da nossa profissão entre as demais. Os resultados mostraram que a enfermagem continuava a ser preferida por pessoas do sexo feminino e que também era a única em que preponderavam os elementos solteiros. A média aritmética das idades do grupo era a mais baixa entre todas as profissões esturadas (39.1) anos. Em relação à naturalidade dos participantes do inquérito, apenas $22.3 \%$ dos enfermeiros haviam nascido na cidade do Rio de Janeiro. O maior contingente era representado pelos na- 
turais da região Nordeste do Brasil, ao contrário dos demais profissionais em relação aos quais o deslocamento observado era basicamente intraregional. Entretanto, sete em dez enfermeiros radicados na Guanabara haviam obtido o seu diploma nas faculdades do Rio cu de Niteroi, o que parece significar que não emigram para outros Estados os elementos aqui formados.

Os dados sobre o exercício profissional mostraram que a supervisão, quer diretamente ligada à atividade prática de enfermagem ou não, envolvia, na maioria das vezes, grupos de até vinte indivíduos, constituídos fundamentalmente por auxiliares de enfermagem $\epsilon$ atendentes. Nesse sentido, a tarefa docente, traduzida no treinamento e aperfeicoamento de outros elementos em serviço, assume especcial importância.

2.3 A Imagem da enfermeira entre estudantes de enfermagem nos Estados Unidos

No artigo "A imagem da enfermeira não está mudando", pubiicado Collins e Jcel (1971) relatam o efeito dos tradicionais estercótipos da enfermagem no recrutamento de candidatos e na sua fixação à profissão. A imagem tradicicnal da enfermeira associa-se à execucão de tarefas que representam cuidados ao paciente. A enfermeira é vista ccmo uma pessoa que alimenta e conforta, executa técnicas e cumpre as ordens médicas. Por cutro lado o hospital ocupa a posição central e preeminente como lccal de prática, na percepcãa da enfermagem como ocupação, atribuida toda ênfase à. narte técnica.

Os autores lembram que esta imagem não se conforma com o mocielo de profissional previsto pelos currículcs de Graduação, de vez que a imagem da enfermeira profissional, segundo aquele modelo caracteriza-se por um desejo de ação independente, de ânsia em experimentar, de renovar, de questionar e de assumir responsabi.iriades.

Conclui também os autores que os estudantes conservam uma idealização altamente técnica ao considerar a enfermagem e que os educadores falharam ao não imbui-los de uma imagem tipicamente profisisonal, com o sentido de devoção à prática que ela inclui.

No estudo "A imagem em estudantes bacharéis". Olsen e Fred, (1966), constataram que, apesar de a imagem profissional poder ser incorporada à medida que se desenvolve a experiência educacional: a imagem tradicional persiste no decorrer do estudo e coexiste com a imagem profissional.

Ao fim do programa os estudantes estão um tanto mais comrrometidos com a nova imagem, todavia retém muito da anterior 
imagem técnica da enfermagem, apesar de terem atingido um nivel comparativamente mais elevado, que poderia propiciar uma visão mais liberal do papel feminino.

As expectativas culturais do papel da mulher em nossa sociedade inibem a interiorização do autoconceito orientado para carreira, que resulta em um padrão difuso e ambíguo da imagem ocupacional. Parece que a indiferença subjacente quanto a uma carreira c a conseqüente falta de comprometimento com a profissão, como 1.al, permitem aos estudantes a liberdade de conceber a enfermagem e as suas relações com ela de modo individual e idiosincrático.

\section{3 - METODOLOGIA}

3.1 População estudada: alunos das fases inicial e terminal dos três Cursos de Graduação das Escolas de Enfermagem existentes no Estado da Guanabara, integrantes da Universidade Federal do Rio (ie Janeiro (UFRJ) , da Universidade do Estado da Guanabara (UEG) c das Federações das Escolas Federais Isoladas do Estado da Guanabara.

Foram escolhidos o primeiro e o sétimo períodos a fim de possibilitar o estudo comparativo da percepcão da imagem da enfermeira por parte dos alunos do ciclo pré-profissional e daqueles que concluiram a formação profissional básica, anterior à escolha da llabilitação.

As escolas foram denominadas A, B e C, de acordo com a ordem cronológica da data de início da coleta de dados. O conjunto das três apresentou um total de 433 alnas matriculados nos períodos citados.

3.2 Recursos: as autoras financiaram os gastos do estudo; entretanto a cooperação de professores e amigos, antes citados. possihilitou a sua realização.

3.3 Prazo: como o trabaiho deveria ser apresentado no XXY Congresso Brasileiro de Enfermagem, o seu desenvolvimento ficou subordinado aos prazos estabeleciòos pela Comissāo de Temas do mesmo Congresso.

3.4. Coleta de dados: foi feita pelas autoras, mediante a aplicação de um questionário. A Diretoria da Escola Ana Néri forneceu carta de apresentação para as diretoras das duas outras Escolas de Enfermagem, bem como para os Diretores dos Centros Biomédicos. onde estudam os alunos de enfermagem no primeiro período letivo. Essas cartas foram entregues aos destinatários durante entrevista previamente solicitada. ocasiāo $\mathrm{em}$ que se interpretou a finalidade co estudo e foram aprazados os dias para a aplicação dos quesinnários. 
A receptividade ao preenchimento do questionário foi muito boa por parte dos alunos que demonstraram grande interesse em responder às perguntas, o que foi feito em classe, com a presença de, pelo menos, uma das autoras. Antes de se distribuirem os formulários explicava-se a finalidade da pesquisa, a importância da colaboração de cada aluno para o bom êxito do trabalho e a pesquisadora colocava-se à disposição de todos para qualquer esclarecimento. Não houve recusas. O máximo de tempo gasto para a aplicação do questionário em uma classe foi de cerca de 30 minutos, conforme havia sido previsto.

No questionário figuravam, além do nome da escola, o ano do vestibular, a turma e os dados referentes aos atributos pessoais, como idade, sexo, estado civil e naturalidade. Os alunos foram indagados sobre:

- o grau de influência da enfermeira na sua escolha pelo Curso de Enfermagem;

- a função peculiar da enfermeira;

- os valores que julgam ser prioritários para as enfermeiras;

- a aspiração maior da enfermeira moderna;

- a posição da enfermeira entre as demais carreiras universitárias;

- a possibilidade de a enfermeira compatibilizar o seu próprio papel com o papel feminino.

3.5 Apuração, tabulação e tratamento estatistico dos dados: foram feitos pelas autoras, manualmente; a organização das tabelas visou a anáiise comparativa por Escola e por período letivo. As tabelas de números 1 e 2 referem-se ao número de questionários respondidos e ao seu percentual em relação ao total de alunos matriculados nos dois periodos letivos estudados e à contribuição de cada escola e de cada periodo para o total de questionários.

As tabelas de números 3 a 5 referem-se aos atributos individuais dos sujeitos estudados e tem por finalidade apenas caracterizar a população matriz. Estas cinco tabelas apresentam distribuição numérica e percentual. Para os dados da tabela n. 3 foi calculada a moda das idades dos alunos das três escolas, por período letivo.

As demais tabelas (de 6 a 11) apresentam os dados relativos à imagem da eniermcira percebida pelos alunos. Para essas tabelas (de 6 a 11) foi aplicado o teste $F$, para análise de variância, entre os totais dos ciois periocios das três escolas, entre os seus periodos, bem como os sétimos, a fim de se veriticar se as diferencas obserypdas entre os períodos e entre as escolas eram significantes.

A tabela 8 refrente aos valores scciais, que os alunos julgaram fossem considerados pelas enfermeiras os mais importantes, teve 
sua tabulação modificada em relação ao projeto inicial. Os alunos ao responderem ao questionário, foram solicitados a numerar os sete valores em ordem da maior para a menor importância, entretanto durante a apuração deliberou-se apurar apenas o valor considerado preeminente.

A tabela 10, referente à posição relativa da enfermagem entre as demais carreiras universitárias, também teve o seu plano modificado. Solicitou-se aos alunos que indicassem as profissões que sugeririam se tivesse eles que orientar jovens na escolha de uma carreira, respeitando as tendências dos orientados pelas áreas de estudo, com três opções para cada área (biomédica, humanística e tecnológica). Entretanto, na tabulação considerou-se apenas a primeira opção para a área biomédica.

Em relação à opinião dos estudantes sobre o grau de interferência da carreira de enfermeira no papel de mãe, esposa e dona cie casa, os dados foram inicialmente organizados por sexo e estado civil; entretanto, como se verificou pelo tratamento estatístico que as diferenças de opinião entre as mulheres solteiras e casadas não eram siginficativas, ao mesmo nível utilizado, este plano foi abandonado. O sexo masculino não foi estudado porque o número de casos observados foi pequeno. A tabela 11 mostra a apresentação geral desses dados.

\section{4 -- ANÁLISE DOS DADOS}

\subsection{Caracteristicas da população}

4.1.1 População matriz: 88,9\% dos alunos matriculados nas duas séries estudadas responderam ao questionário, isto é 385 questionários para 433 alunos matriculados nas escolas A, B e C, variando de $86,9 \%$ na escola $A$ e $90,3 \%$ na escola $C$ (tabela 1 ).

4.1.2 Composição da população matriz: cada escola (A, B e C) contribuiu para o total de questionários com uma proporção semelhante às demais, $31 \%, 35 \%$ e $34 \%$, respectivamente.

Os dois períodos letivos estudados deram contribuição semelhante ao total de questionários respondidos: $55.3 \%$ para o primeiro e $44,7 \%$ para o sétimo (tabela 2 ).

4.1.3 Idade: $86,0 \%$ dos alunos situaram-se entre as idades de 15 a 29 anos, sendo que $55,6 \%$ ficaram na classe de 20 a 24 anos. A moda das idades foi de 22 anos, sendo 21,4 anos para o primeiro período e 22,8 anos para o sétimo período (tabela 3 ).

4.1.4 Estado civil: $88,4 \%$ dos alunos que responderam ao questionário são solteiros, e a proporção mais alta corresponde aos alu- 
nos do primeiro período $(93 \%)$; no sétimo período $82,6 \%$ são solteiros (tabela 4).

4.1.5 Sexo: $87,3 \%$ dos alunos pertencem ao sexo feminino, sendo que o maior percentual foi o da Escola B $(96,3 \%)$ e o menor o da Escola C $(77,1 \%)$. Também houve diferença entre os períodos estucados: $84,5 \%$ para o primeiro e $90,7 \%$ para o sétimo. No primeiro período, o percentual mais alto foi o da Escola B (100\%) e o mais baixo o da Escola C $(77,1 \%)$, tabela 5$)$.

4.1.6 Naturalidade: das $83,9 \%$ de alunos que se declararam brasileiros, $64,7 \%$ são da região Sudeste e $14,7 \%$ do Nordeste, as demais regiões não tiveram contribuição significativa. O Estado da Guanabara contribuiu com $72,3 \%$ das respostas da região Sudeste e $55,7 \%$ do total de todos os Estados.

\subsection{A Imagem da Enfermeira percebida pelos estudantes}

O teste de análise de variância aplicado aos dados das tabelas referentes ao tema demonstrou não haver diferenças significativas entre o total dos dois períodos das três escolas, nem entre os períodos correspondentes das três escolas; o grau de confiança utilizado foi de $95 \%$. Deste modo as hipóteses de trabalho não foram confirmadas.

Assim, as respostas dos 385 alunos que responderam ao questionário foram analisadas como um todo homogêneo.

4.2.1 Grau de influência da enfermeira na escolha da carreira pelos estudantes: apenas $2,7 \%$ dos alunos foram fortemente influenciados por uma enfermeira; $16,9 \%$ sofreram uma influência regular, através de outros membros da equipe de saúde que não a enfermeira, do orientador vocacional ou de parentes e amigos; 5,4\% sofreu uma influência fraca, através dos meios de comunicação e de conversas em geral. 75,9\% não identificaram influência da enfermeira na escolha, declarando haver escolhido a profissão por uma decisão essencialmente pessoal. Alguns afirmaram não haver conseguido vaga no curso que desejavam (tabela 6 ).

4.2.2 Opinião dos alunos sobre a função peculiar da enfermeira: $\mathbf{7 4 , 8 \%}$ dos alunos identificaram o diagnóstico e o plano assistencial de enfermagem ("em que e como deve ser o paciente assistido") como a função precípua da enfermeira. A observação e vigilância do paciente para anotação na papeleta foi considerada função precípua por $7,5 \%$ dos alunos e o treinamento do pessoal auxiliar por $6,7 \%$. As demais funçōes não obtiveram percentagem apreciável (tabela 7). 
4.2.3 Opinião dos alunos sobre os valores que julgam ser pricritários para as enfermeiras: em um conjunto de sete valores sociais, a educação, a saúde e o trabalho foram os mais indicados, com $35,3 \%, 29,6 \%$ e $20,2 \%$ respectivamente. Os demais valores (segurança, diversão, dinheiro e moradia), não obtiveram percentagem apreviável (tabela 8).

4.2.4 Opinião dos alunos sobre a maior aspiração da enfermeira moderna: $43,3 \%$ dos participantes do inquérito julgam ter um status condizente com a dignidade da profissão constitui a maior aspiração da classe e $34 \%$ julgam que "exercer uma profissão em que se realiza ao dar contribuição de valor na equipe de saúde" seria esta aspiração. Dos demais valores, apenas "progredir na carreira" obteve im percentual apreciável: $12,5 \%$ (tabela 9).

4.2.5 Posição da Enfermagem entre as demais carreiras universitárias da área das Ciências da Saúde: $52,1 \%$ dos alunos indicaram a enfermagem como a carreira que sugeririam, como primeira opção, para jovens que desejassem escolher uma profissão na área biomédica. $37,1 \%$ sugeririam a medicina. A opinião dos ciemais alunos $(10,8 \%)$ estava distribuida entre outras oito profissões (tabela 10).

4.2.6 Opinião dos alunos sobre o grau de interferência da carreira da enfermeira no papel de mãe, esposa e dona de casa: o percentual dos alunos que julgaram a carreira da enfermeira incompatível com o papel de mãe, de esposa e de dona de casa não foi importante $(3,1 \%, 3,6 \%$ e $6,2 \%$ respectivamente).

Mais de um terço julgou que a carreira não interfere nesses papéis femininos (32,9\% para o de mãe; $43,4 \%$ para o de esposa e $33,5 \%$ para o de dona de casa).

Os demais alunos situaram-se entre estes dois extremos, diviäindo sua opinião entre "interfere muito" e "interfere pouco". Pouco mais de um terço desses alunos julgou que a carreira interfere muito no papel de mãe $(34,3 \%) ; 26,8 \%$ acharam que interfere pouco no papel de esposa e no de dona de casa $(32,2 \%$ e $34,3 \%$ respectivamente). 17,7 e 23,1 foram os percentuais encontrados para os que julgaram que a carreira interfere muito no papel de esposa e no de dona de casa respectivamente (tabela 11 ).

\section{5 - INTERPRETAÇÃO DOS DADOS}

5.1 Caracteristicas da População: Dentre os atributos estudados merecem comentário o sexo e a naturalidade.

A enfermagem é uma profissão tradicionalmente feminina e tal fato foi confirmado no estudo feito por Monteiro de Castio e 
outros no Estado da Guanabara, (1970), sobre as caracteristicas tos profossionais da área da saúde. Entretanto, a Reforma Universitária (1966|67), ao determinar a abertura das escolas a ambos os sexos e o vestibular unificado, fizeram com que os candidatos pudessem optar por três cursos em que desejassem se matricular, de acordo com sua classificação. Assim, a partir de 1971, começou a ingressar nos Cursos de Graduação em Enfermagem um número crescente de alunos do sexo masculino, conforme demonstra a diferença entre o primeiro e o sétimo períodos letivos das escolas, correspondentes aos vestibulares de 1970 e 1973 (15e 31 estudantes do sexo masculino, respectivamente).

Quanto à naturalidade, o mesmo estudo acima citado refere que apenas $22,3 \%$ dos enfermeiros em exercício haviam nascido na cidade do Rio de Janeiro, embora $70 \%$ deles houvessem obtido seu diploma nas faculdades do Rio ou de Niteroi. O percentual observado agora neste trabalho foi de $55,7 \%$ de estudantes cariocas, sendo que, em relação à região sudeste, esta proporção sobe para $72,3 \%$. O percentual dos alunos naturais da região sudeste foi de $64,7 \%$. Estes dados poderiam ser atribuidos a uma diminuição de regionalização do ensino.

\subsection{A Imagem da Enfermeira Percebida pelos estudantes}

O percentual de estudantes que identificaram a influência direta ou indireta da enfermeira, na sua escolha da profissão $(24,1 \%)$ parece indicar que as enfermeiras não têm servido como modelo para a comunidade, pois na verdade apenas 2 alunos em 10 conseguiram identificá-la como tal.

$\mathrm{O}$ alto percentual de alunos que identificaram o diagnóstico e - plano assistencial de enfermagem como a função precípua da enfermeira $(74,8 \%)$ mostra uma imagem altamente profisisonal, de acordo com o consenso existente entre as líderes da classe. Os dois nutros itens que obtiveram percentagem apreciável, "observação e vigilância do paciente" (para registro) e "treinamento do pessoal auxiliar", apesar de não constituirem a sua função precípua, são realmente atribuições específicas da enfermeira.

Os valores considerados pelos alunos como prioritários para as enfermeiras - educação, saúde e trabalho - atribuem um alto grau de compromisso das mesmas enfermeiras com a profissão, o que é reforçado pelas respostas à questão seguinte, onde a melhoria cio status profissional foi considerada a maior aspiração da classe $(40,3 \%)$. Esta suposição coincide com a atual fase de evolução da enfermagem em todo o mundo de um modo geral e, em participar, 
da enfermagem brasileira. Por outro lado, demonstra que os estudantes julgam haver uma insatisfação com o status atual da enfermeira. O desejo, perfeitamente legítimo, de melhoria de status mostra uma posição pragmática em relação à profissão; entretanto, cerca de um terço dos estudantes (34\%) atribuiu às enfermeiras uma posição mais idealista, em que sua maior aspiração seria "dar contribuição de valor na equipe de saúde". Nesta afirmativa, além de estar implícito o ideal de servir, faz-se também presente uma atitude profissional moderna: a do trabalho em equipe. A terceira aspiraçäo apontada, com $12,5 \%$ de referência progredir na carreira" - reforça a imagem profissional já sugerida.

Apenas cerca da metade $(52,1 \%)$ dos alunos julgou a enfermagem como a melhor carreira a ser preferida pelos jovens que desejam escolher uma profissão na área da saúde. Mais de um terço $(37,1 \%)$ considerou ser a medicina a profissão mais desejável. Estes ciados sugerem que determinadas profissões mais antigas ainda exercem grande atração sobre os jovens, tendo alguns deles inclusive declarado que haviam optado no vestibular por outra profissão. Vale lembrar que esta opinião foi dada por um grupo sem experiência profissional e que seu ajustamento à profissão provavelmente vaí dcpender das oportunidades que encontrar na carreira.

As respostas à possibilidade de a enfermeira conciliar o seu papel profissional com o papel feminino de mãe, esposa e dona de casa parecem indicar ser isto possível embora com certo grau de dificuldade. Vale lembrar que o grupo não tem experiência nesse assunto $(88,4 \%$ é de solteiros e ainda não estão no exercício da profissão). Entretanto, a comparação entre as respostas das muIheres solteiras e das casadas, embora limitada pelo pequeno número destas, não evidenciou diferenças significativas.

O papel da mulher em nossa sociedade vem sofrendo modificações crescentes à medida em que se processa a emancipação feminina. Assim, a enfermeira enfrenta hoje toda a dificuldade de uma fase de transição. A dificuldade maior parece relacionou-se ao papel de mãe (343\% "interfere muito") talvez porque a comunidade não ofereça facilidades especiais às mães que trabalham fora de casa.

Esse fato se ajusta ao desejo traduzido na afirmação de Pierre Furter, de que a mulher "também tem o direito de se desenvolver profisisonalmente e muitas vezes isto entra em conflito com o que se espera dela como mãe de família... E justamente aí está a grande contradição das sociedades modernas, que esperam que a mulher realize seu papel de reprodutora, para que a sociedade permaneça c ao mesmo tempo solicitam a mão de obra feminina para o mercado de trabalho". 


\section{$\epsilon$ - CONCLUSÕES}

A imagem da enfermeira percebida pelos estudantes do Curso de Graduação de Enfermagem é altamente positiva: as funções, as aspirações e os valores a ela atribuídos refletem um profundo comprometimento desta com a carreira que abraçou.

Esta imagem favorável não condiz com o achado de que a enfermeira não tem servido de modelo para os estudantes que escolhem a carreira de enfermagem.

Não houve, como se viu, diferenças significativas entre os alunos das três escolas estudadas e. o que é surpreendente, também não se registraram divergências entre os alunos do primeiro e do sétimo periodos. A imagem positiva que tem o estudante do enfermagem da cufermeira ele já a traz ao ingressar na escola.

\section{? - RECOMENDACÕES}

Ás Diretoras c professoras das Escolas de Enfermagem:

- que procurem avaliar a imagem da enfermeíra percebida pclos estudantes ao final do curso, em relação àquela que trouxeram ao ingressar na escola. de modo a adequar as experiências educacionais propcrcionadas aos estudantes às modificações desejadas.

À ABEn Central e Seções Estaduais:

- que procurem juntar os seus esforços de divulgação de uma nova imagem da enfermeira aos esforços dos órgãos governamentais interessados em corrigir as distorçōes do ensino superior e do merrado de trabalho, fornecendo-lhes modelos adequados para consumo da população.

\section{BIBLIOGRAFTA}

\section{LIVROS:}

ALCÅTARA. G. de - A enfermagem moderna romo categonia profissional: obstáculos à sua expransão na sociedade brasileira. (Tese de concurso à cátedra de história da enfermagem e ética da escola de Ribeirão Preto. Ribeirão Preto, 1966.

CARVAIHO, I. M. - Introdução à filosofia das relações humanas - Rio de Janeiro, F. G. V.. 1969.

AVILA, F. Bastos de. S. I. -.- Pequena enciclopédia de moral e civismo. Rio de Janeiro, MEC, 1967.

JASPERS, D. Ludgero, O. S. B. - Manual de filosofia $-5^{a}$ ed. São Paulo, Editora Melhoramentos, 1932.

IELLO UNIVEFSAI, dicionário enciclopedices luso-brasileire, lumes, I,elles /s.d.! 
LOUWE, P. H. Chombart de - Imagens da mulher na sociedade. São Paulo, Editora Senzala, 1967.

WEBSTER, N. - The consolidated. Webster Compreensive enciclopedia dictionary. Chicago, Consolidated book publishing, 1957.

\section{PUBLICAÇŌES DIVERSAS:}

ASSOCIAÇAO BRASILEIRA DE ENFERMAGEM -- I.evantamento de re cursos e necessidades de enfermagem; sumários mimeografados, Rio de Janeiro, 1959.

ALCANTARA, G. - o pessoal de enfermagem necessário em face da realidade sócio-econômica do Brasil, (mimeografado) Pibeirăo Preto, 1969)

\section{PERIÓDICOS:}

ALCÂNTARA G. de - Formação e aperfeiçoamento da enfermeira em face das exigências modernas. Rev. Bras. Enf. 17 (6): 408-419, 1964.

- Novas tendências na educação da enfermagem. Rev. Bras. Enf. 17 (5): 335-345, 1964.

- Recrutamento e seleção de estudantes (XX Congresso brasileiro de enfermagem, Recife, 1968: $2 .^{\circ}$ simpósio Seleçăo, formação e aperfeiçoamento de enfermeiros). Rev. Bras. Enf., 21 (4): 221$226,1968$.

ALVIM, E. F. - A formação profissional no mundo atual. Rev. Bras. Enf., 20 (4) : 229-234, 1967.

ERINTON, D. M. - Value differences between nurses and low-income families. Nursing Research, 21 (1) jan-febr. 46-52, 1972.

CARVAlho, A. C. - Considerações sobre o curso superior de enfermagem. Rev. Bras. Enf., 14 (5): 452-560, 1961.

COLLINS, D. L. \& JOEL, L. A. - The image of nursing is not changing. Nursing Out look, 19 (7): $456-459,1971$.

CRISTO REDENTOR, M., Ir. PMM - Consideraçōes sobre o curso básico de enfermagem. Rev. Bras. Enf., 18 (4): 239-244, 1965.

MAYOR, D. - A profession ... Its growth and development. Nursing outlook, 11 (1): 33-36, 1963.

OLIVEIRA, M. I. R. de -- Fases de crescimento e desenvolvimento profissional. Rev. Bras. Enf., 16 (6) : 45̄3-460, 1963.

- - A reforma universitária e o curso de graduaçảo para enfermeiras. Rev. Bras. Enf., 20 (4) : 23̄̄-243, 1967,

RESENDE, M. A. \& RIVERA, S. D. - Aceitação da enfemagem como profissão, Rev. Bras. Enf., 13 (3): 382-393, 1960.

TeIXeIrA, A. - Cultura e tecnologia. Rev. Fras. Fst. Pedag. 121; 12-37 jan.-mar., 1971. 


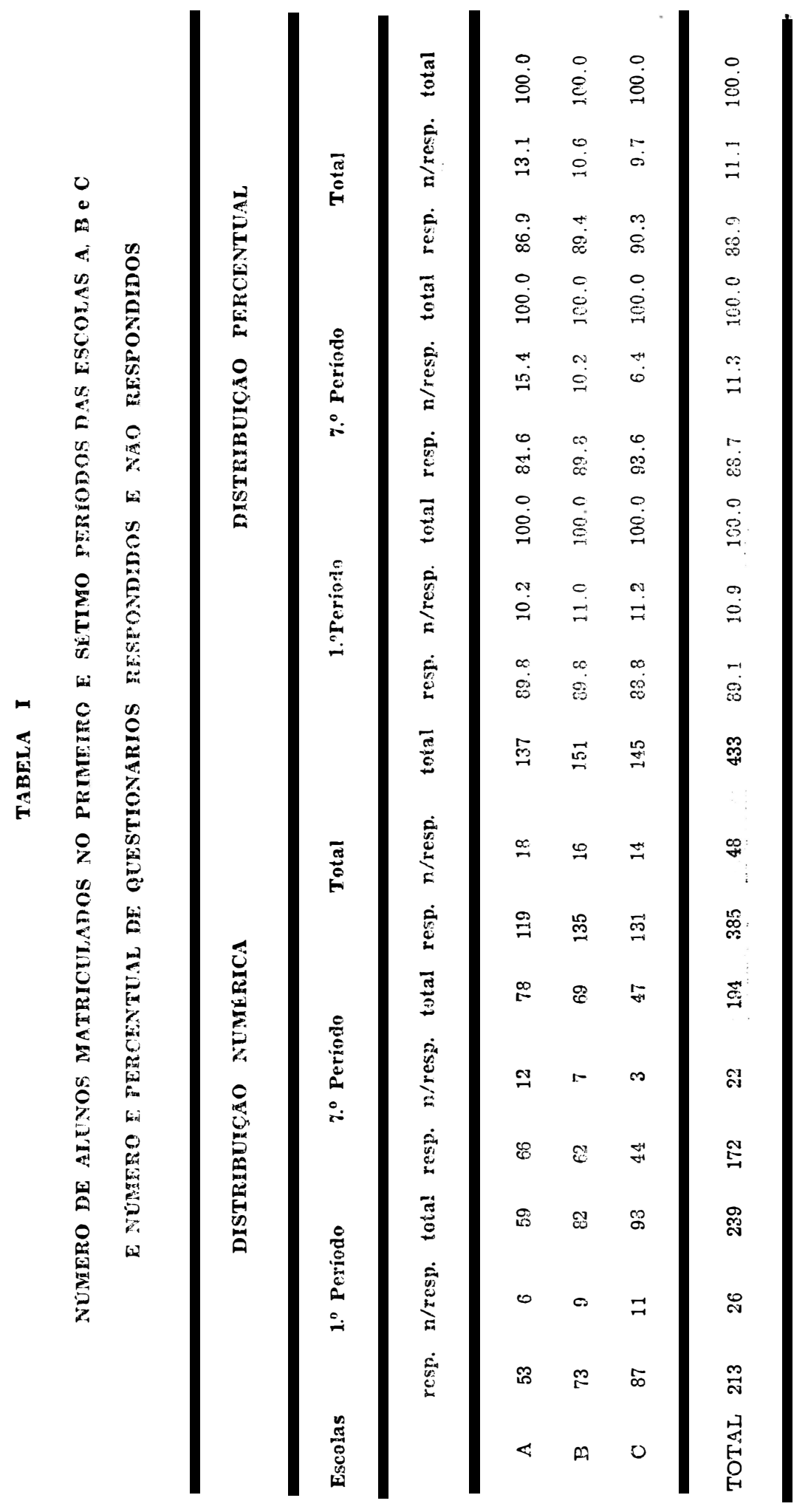




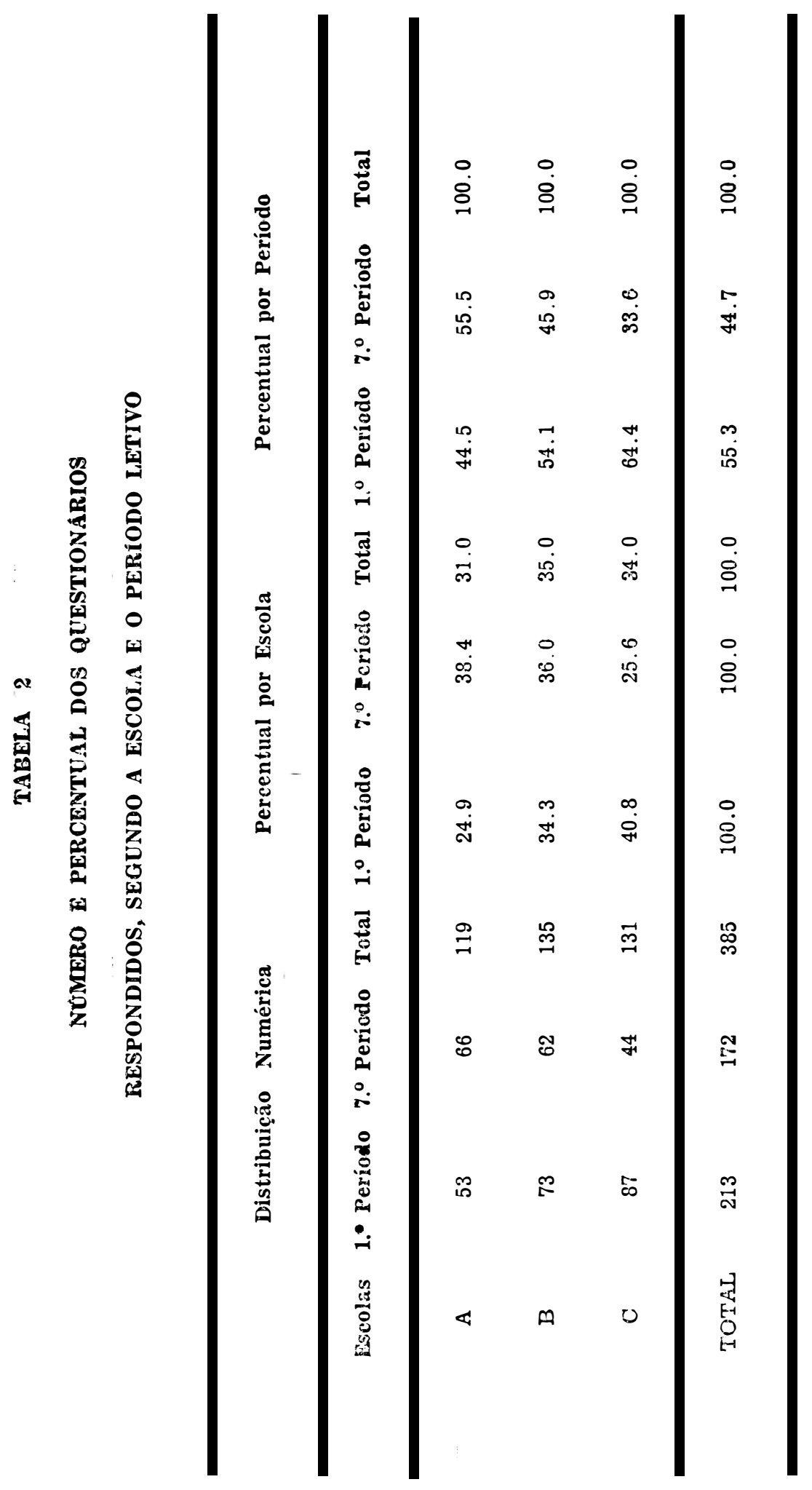




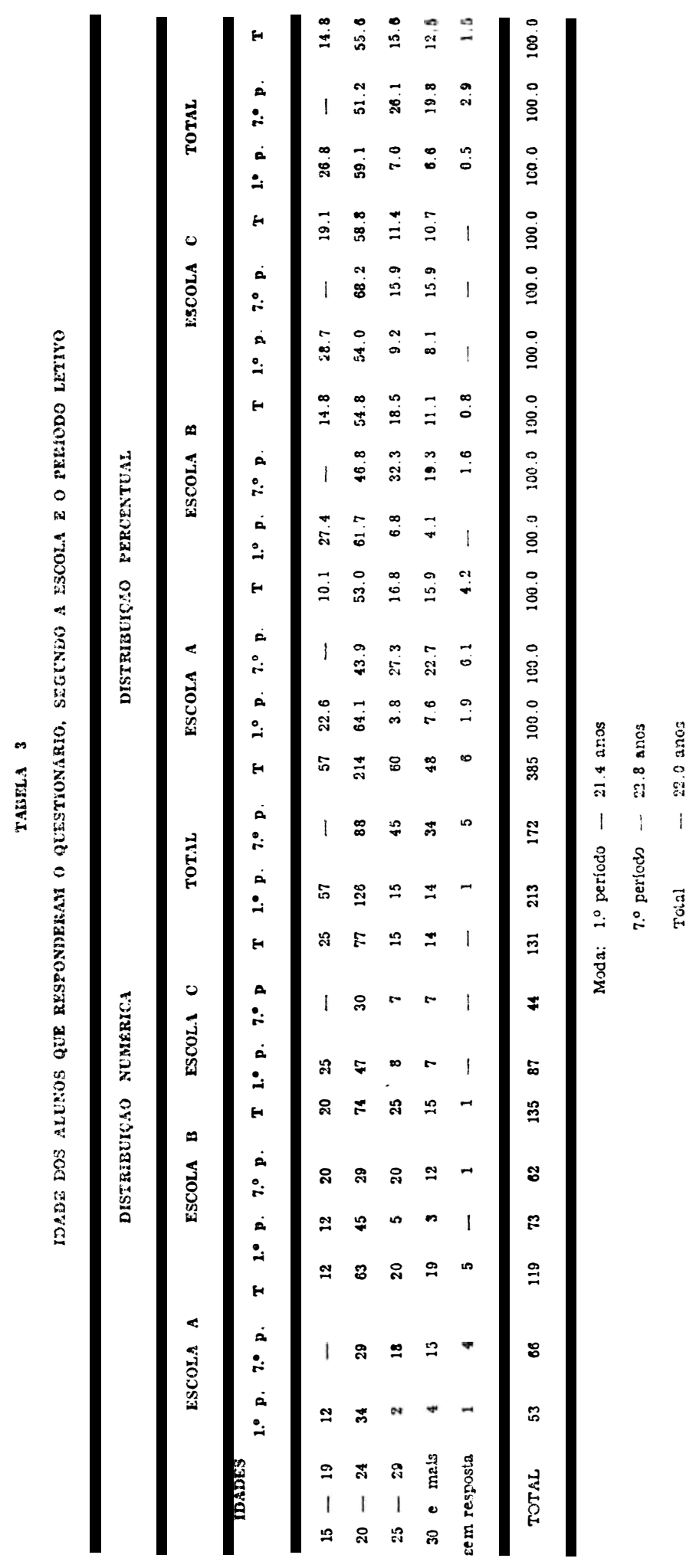




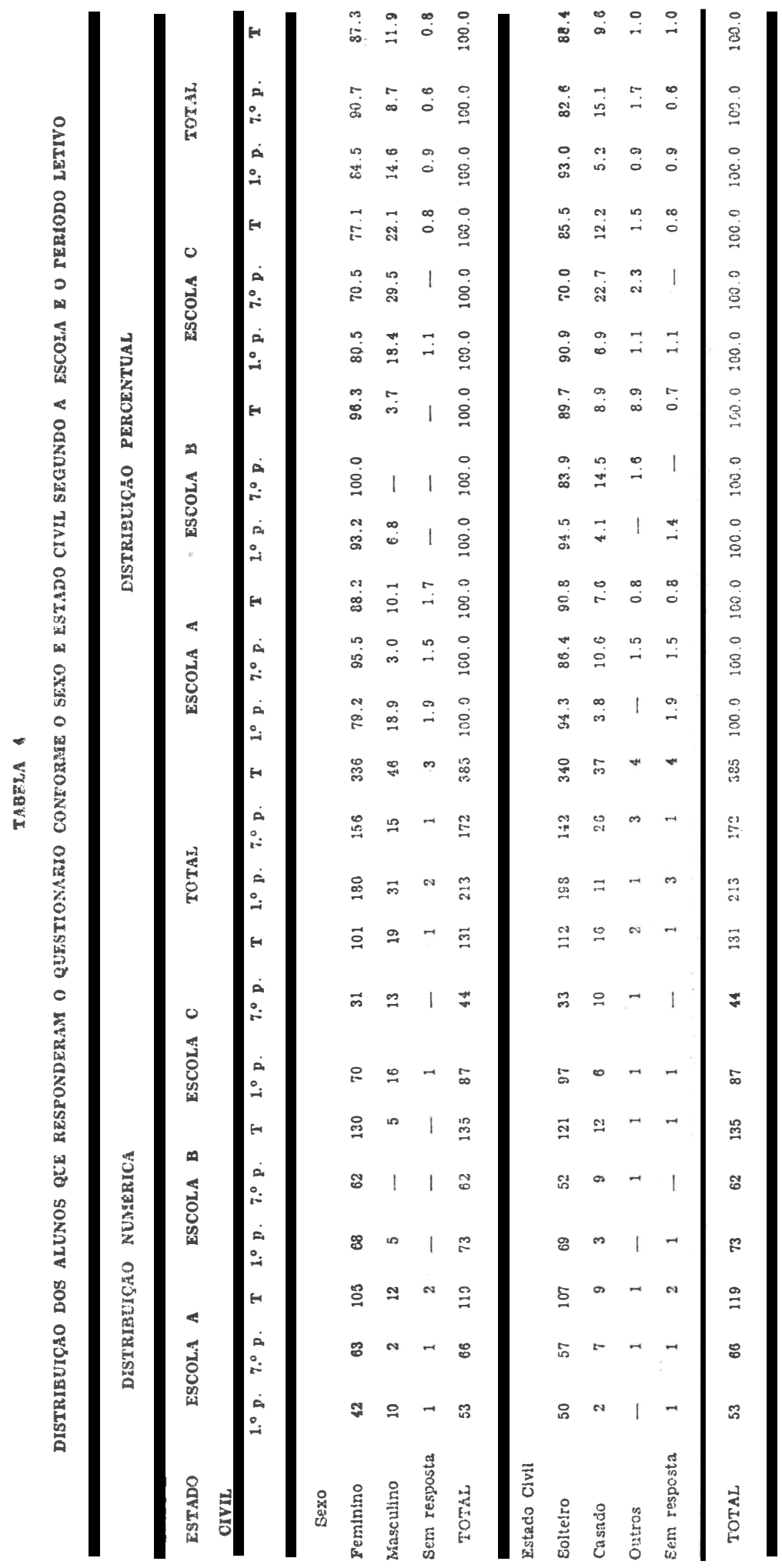




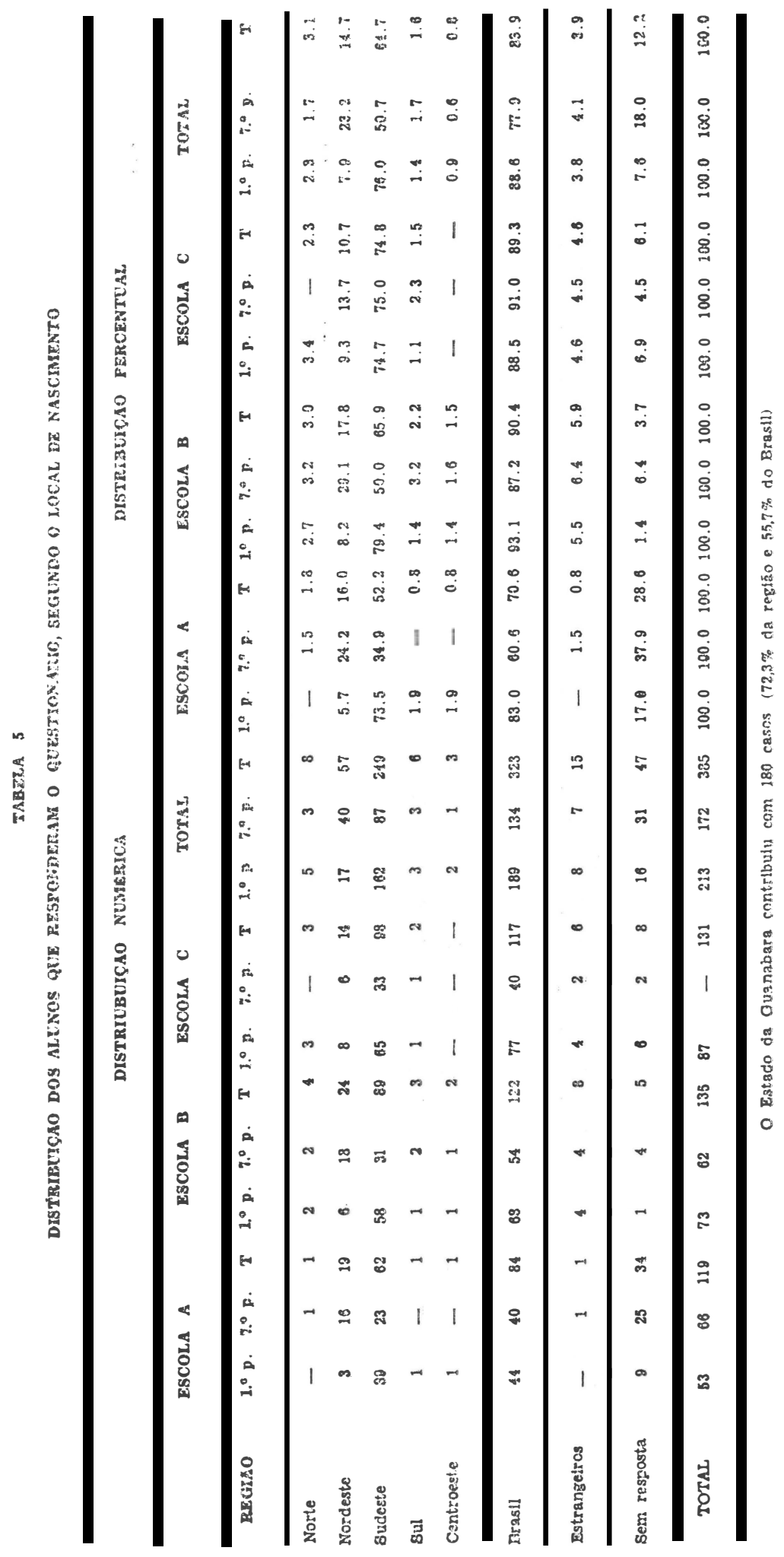




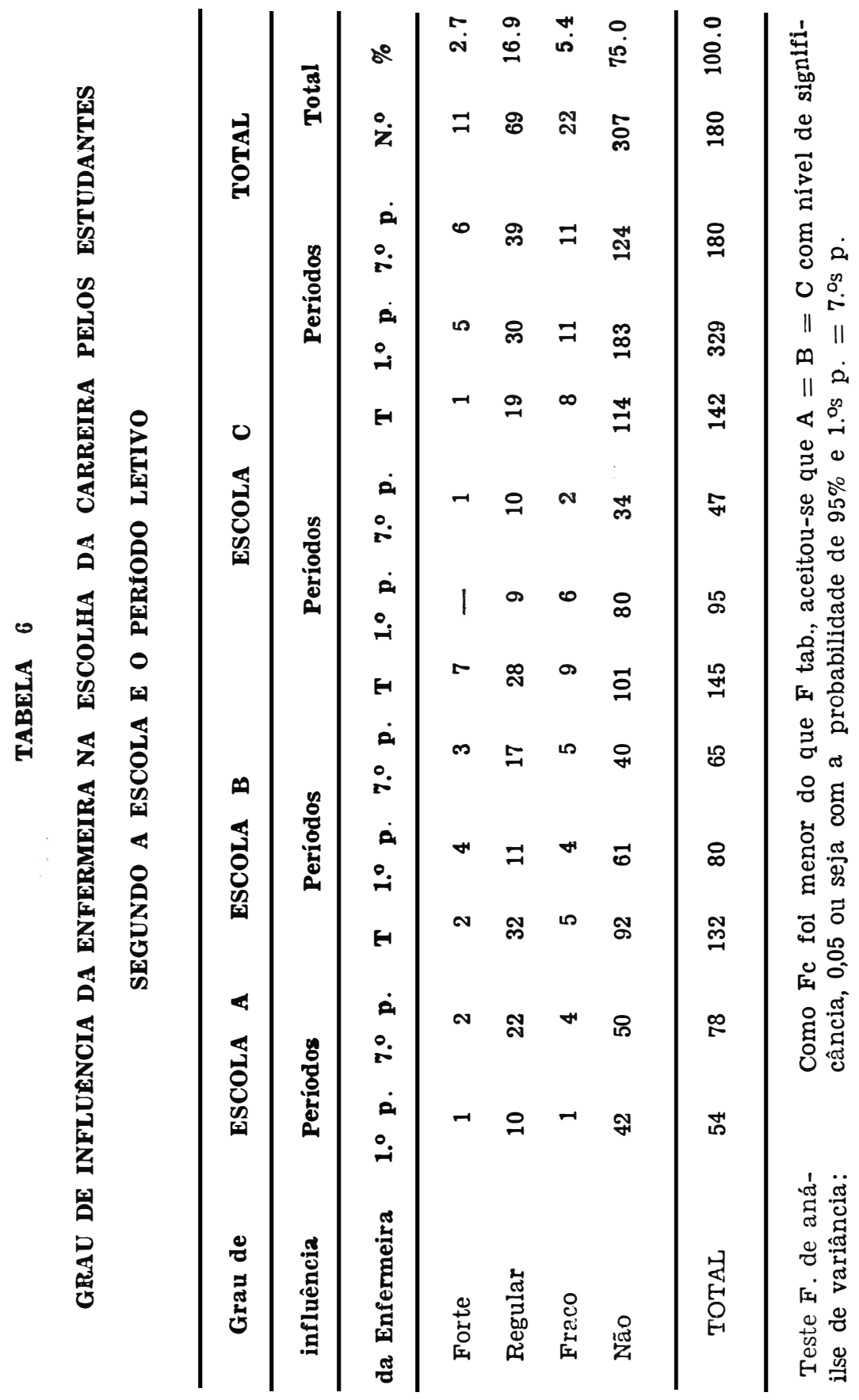




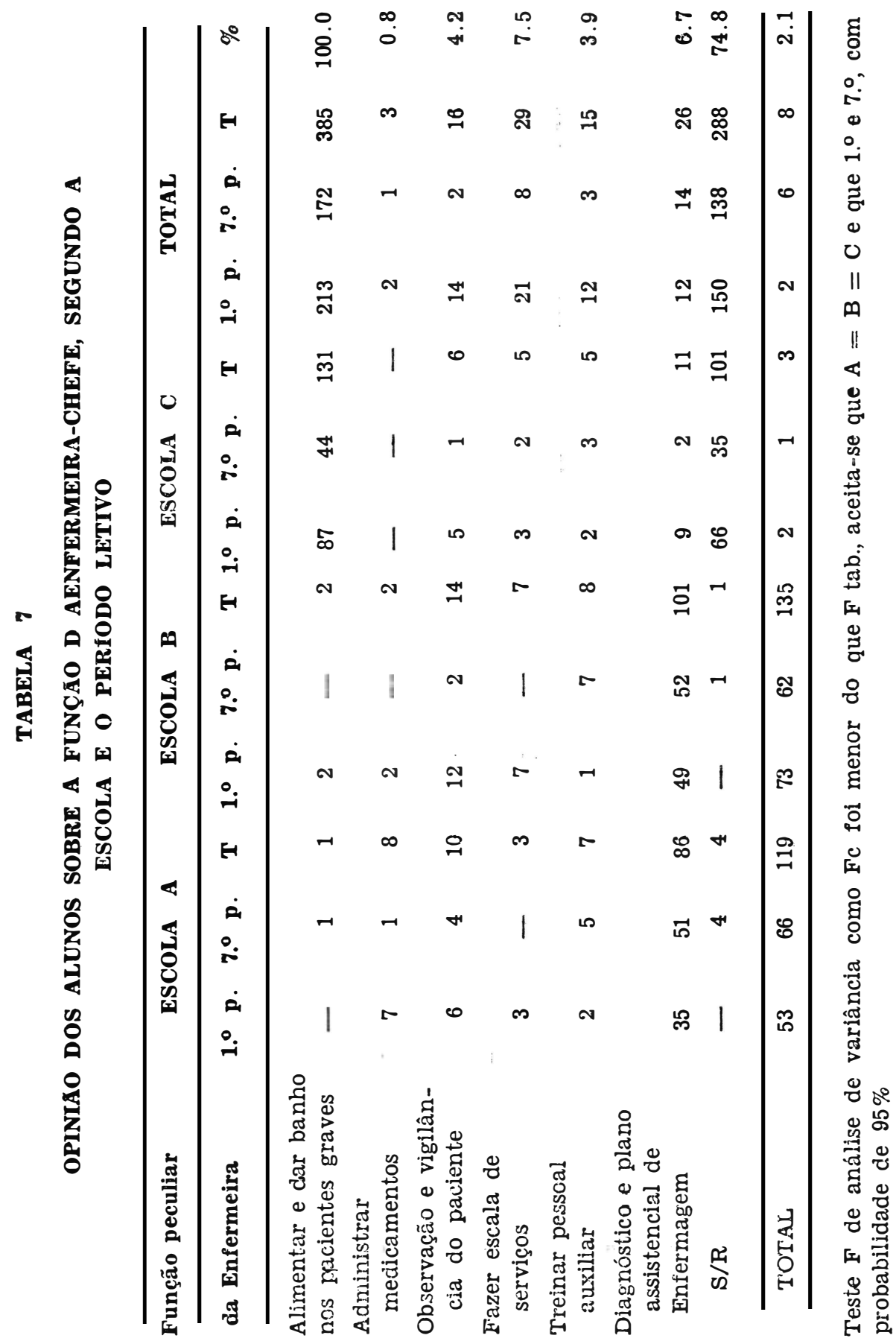




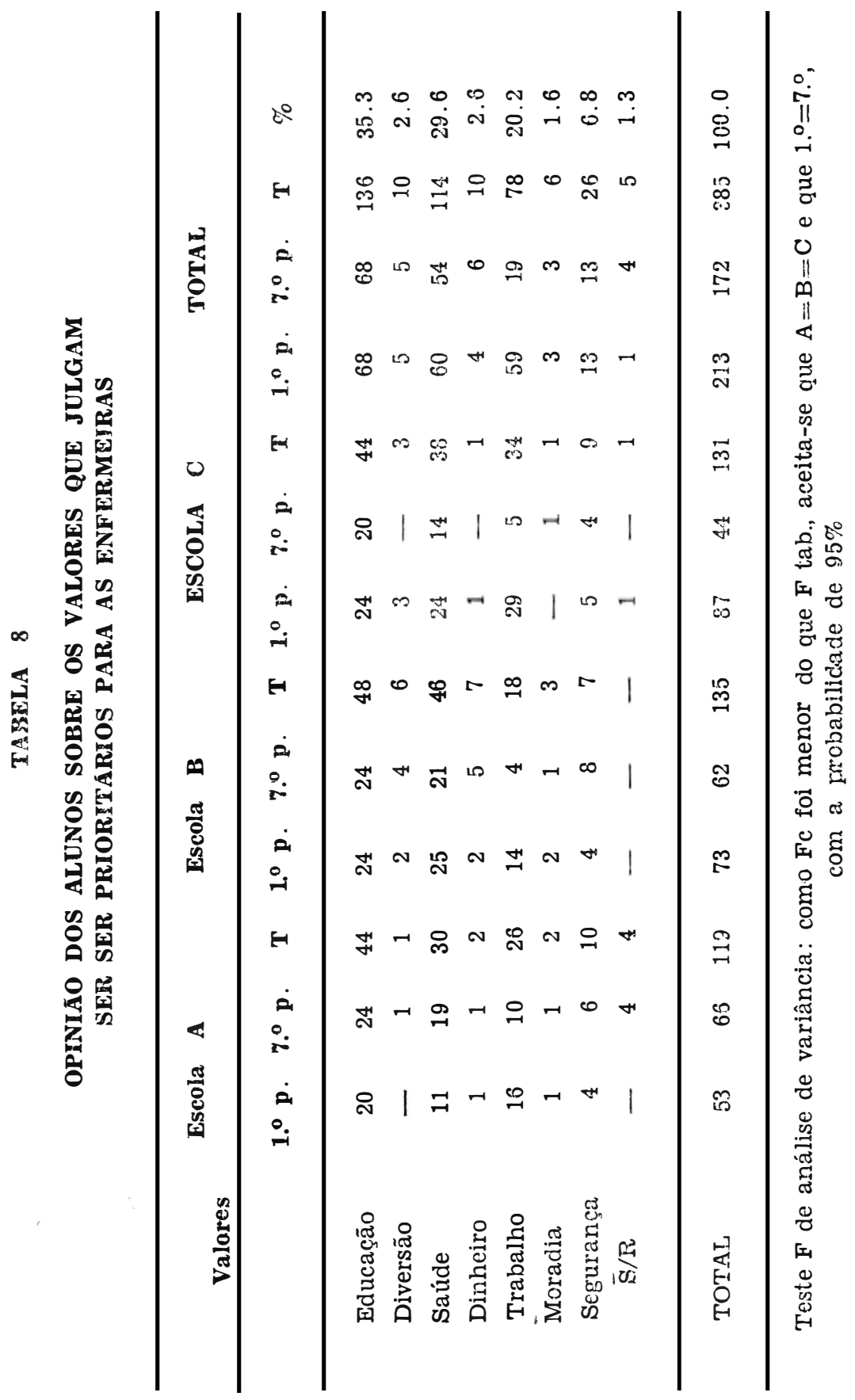




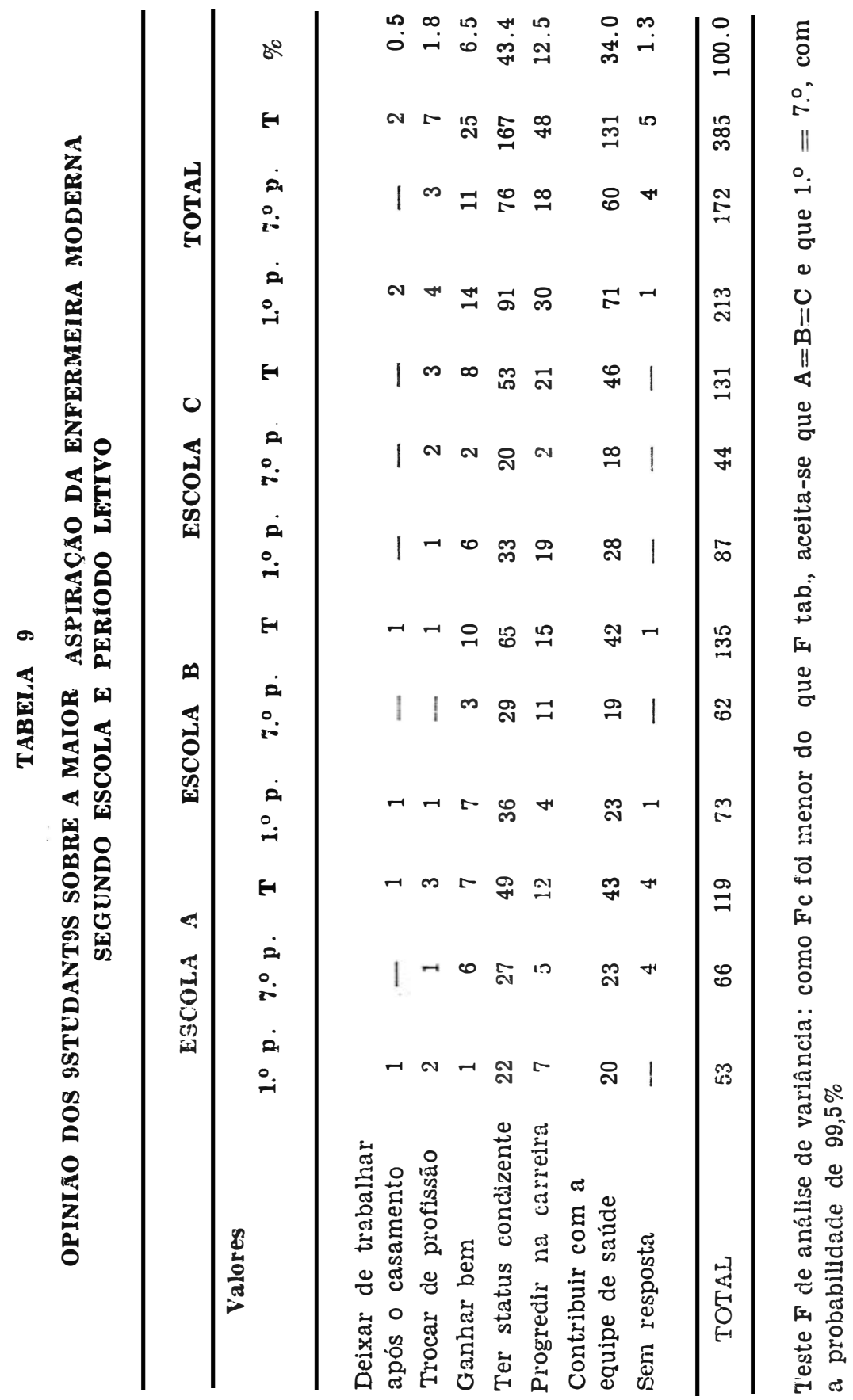




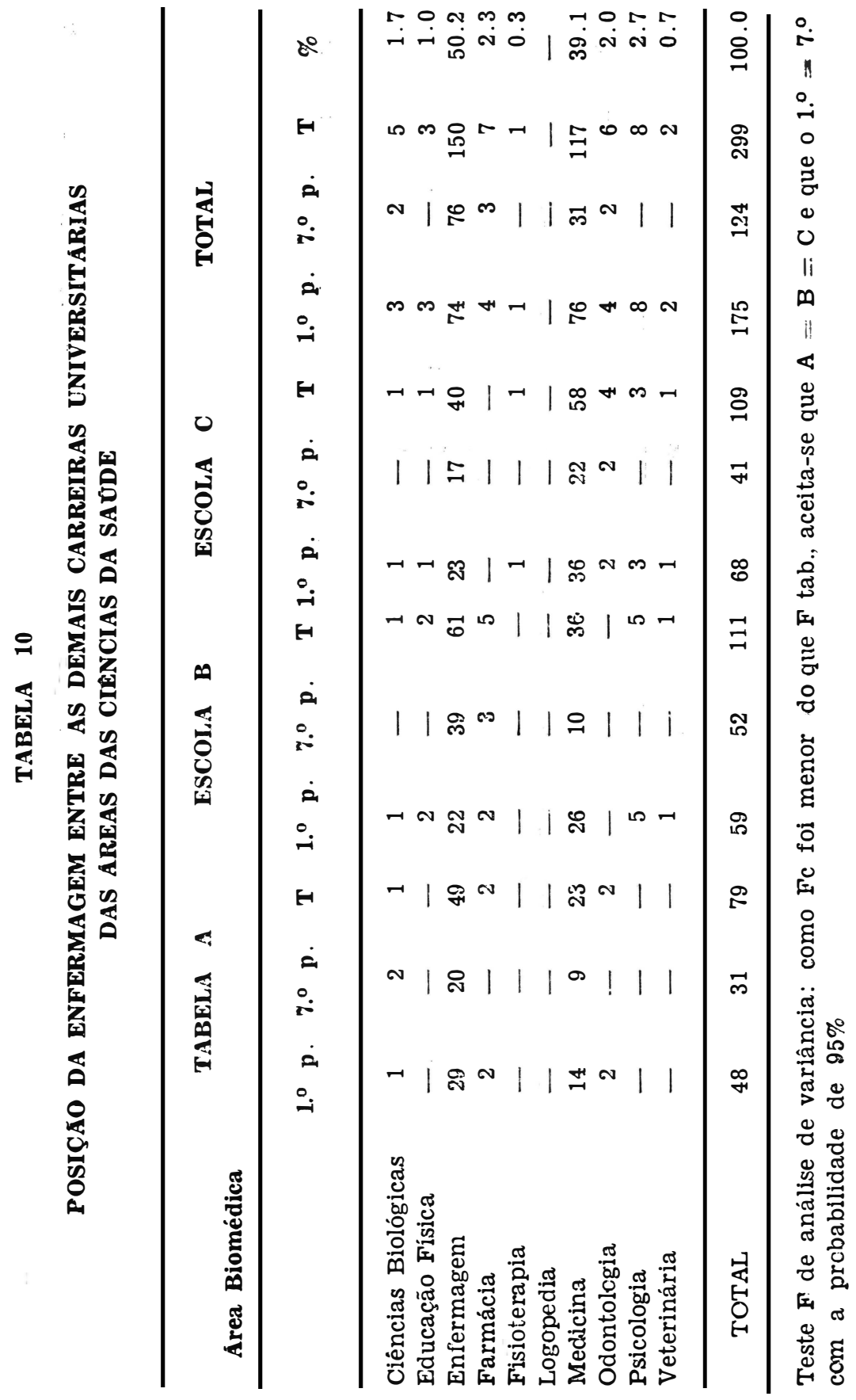




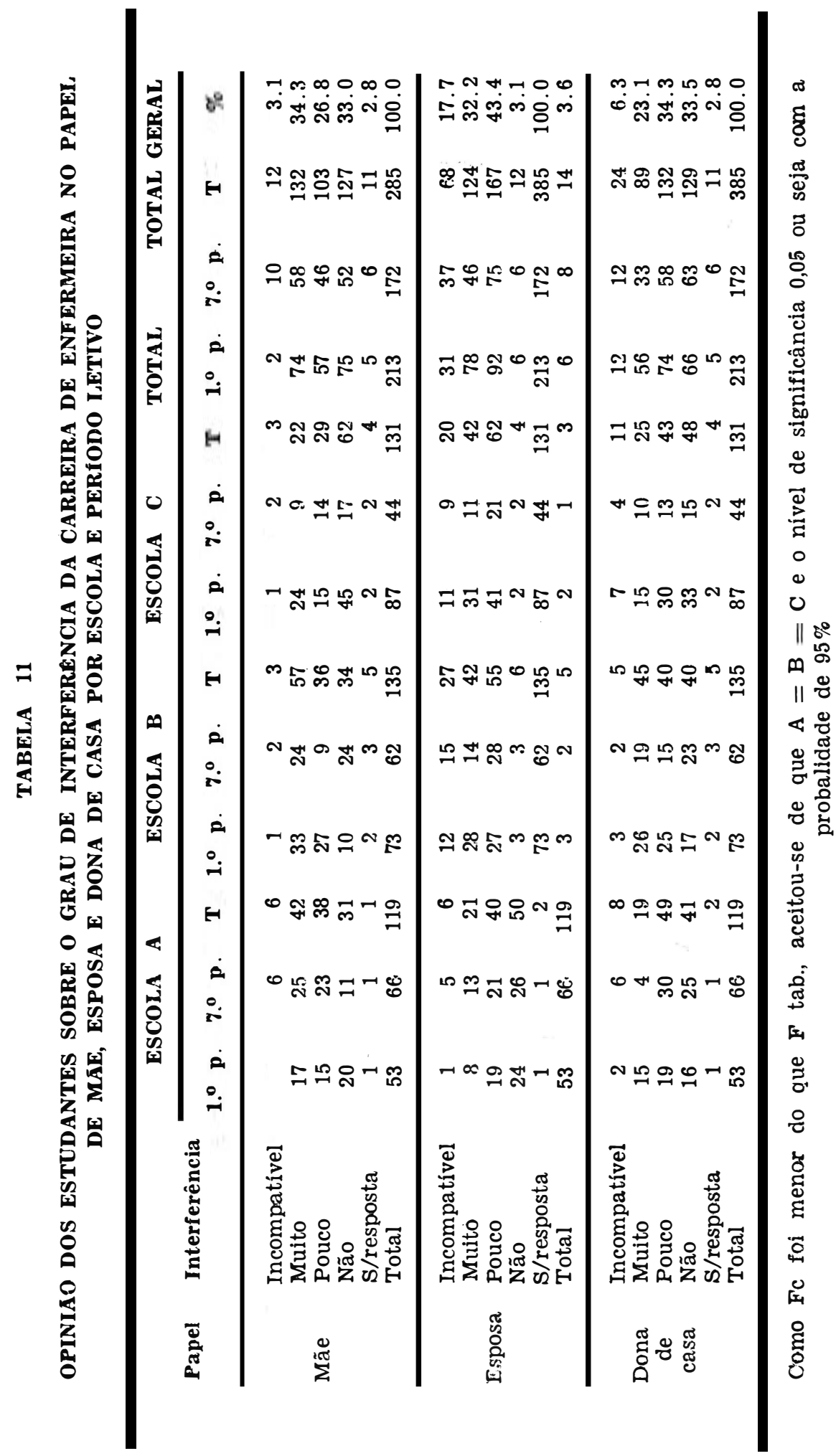


NOME DA ESCOLA

ANO DO VESTIBULAR

TURMA

IDADE

SEXO

ESTADO CIVIL

NATURALIDADE

1 - A sua decisão em seguir o curso de enfermagem resultou de

( ) decisão essencialmente pessoal

( ) conversas casuais com pessoas que não trabalham na área da saúde

( ) influência de parentes e amigos

( ) meios de comunicação (leituras, cinema, televisão)

( ) orientação vocacional

( ) por influência de outro membro da equipe de saúde (médico e outros)

( ) conhece uma enfermeira

2 - Qual a função mais importante da enfermeira responsável por uma unidade do hospital?

(escolher uma resposta apenas)

( ) alimentar e dar banho nos pacientes graves

( ) administrar medicamentos

( ) observação e vigilância do paciente para anotar na papeleta

( ) fazer escalas de serviço para o pessoal de enfermagem

( ) treinar o pessoal auxiliar

( ) identificar em que e como deve ser o paciente assistido.

3 - Numere, em ordem de maior para a menor importância, os seguintes valores como supõe que uma enfermeira responderia

( ) educar-se

( ) divertir-se com os amigos e a familia

( ) conservar sua saúde

( ) economizar dinheiro

( ) trabalhar em um emprego satisfatório

( ) morar em um bom bairro

( ) prover segurança para o futuro 
4 - Dentre os quesitos abaixo, na sua opinião, e segundo o que tem observado, o que a enfermeira moderna tem como ideal ou mais deseja

(escolher uma só resposta)

( ) deixar de trabalhar após o casamento

( ) trocar de profissão

( ) ter um mínimo de mais de 10 (dez) vezes o salário mínimo

( ) ter um status condizente com a dignidade da profissão

( ) progredir na sua carreira

( ) exercer profissão em que se realiza ao dar contribuição de valor na equipe de saúde

5 - Se tivesse que orientar jovens sobre a escolha de uma carreira, respeitando suas tendências pelas áreas de estudo, quais profissões sugeriria?

Área biomédica

$$
\text { 1. opção 2. }{ }^{a} \text { opção } \quad 3 .^{a} \text { opção }
$$

Área humanística

Área tecnológica

6 - Na sua opinião, de que forma a carreira de enfermeira interfere no papel feminino de:

(escolher uma resposta em cada um dos três itens)

1 - MÃE

- é incompatível

- interfere muito

- interfere pouco

- não interfere

2 - ESPOSA

- é incompatível

- interfere muito

- interfere pouco

- não interfere

3 - DONA DE CASA

- é incompatível

- interfere muito

- interfere pouco

- não interfere 